\title{
A 26-Year Review of Emergency Peripartum Hysterectomy in a Tertiary Teaching Hospital in Kuwait - Years 1983-2011
}

\author{
Rachana Chibber ${ }^{a, b}$ Jassim Al-Hijji ${ }^{b}$ Mohamed Fouda ${ }^{b}$ Eyad Al-Saleh ${ }^{a}$ b \\ Abdul Razzak Al-Adwani ${ }^{\mathrm{b}}$ Asiya Tasneem Mohammed $^{\mathrm{a}}$ \\ ${ }^{a}$ Department of Obstetrics and Gynaecology, Faculty of Medicine, Kuwait University, Jabriya, and \\ ${ }^{b}$ Department of Obstetrics and Gynaecology, Al-Adan Hospital, Ahmadi, Kuwait
}

\section{Key Words}

Peripartum emergency hysterectomy $\cdot$ Haemorrhage $\cdot$

Risk factors

\begin{abstract}
Objective: To identify the risk factors and study the incidence, indications and complications of emergency peripartum hysterectomy (EPH). Materials and Methods: This was a retrospective case-control study. The cases consisted of all women who underwent EPH between January 1983 and January 2011. Two controls per case were randomly selected from the remaining deliveries by using a random number table. Case records were retrieved from the medical records. Results: Among 150,993 deliveries, there were $59 \mathrm{EPHs}$ (cases), giving a rate of 0.390 per 1,000 . Of the 59 cases, only 56 were analysed because 3 files were unavailable. These women were older (mean age $36 \pm 5.7$ vs. $22 \pm 5.3$ years, $p<0.01$ ) and had delivered more than 1 child $(p=0.02)$. Thirty-seven $(66 \%)$ cases had had previous caesarean sections (CSs) and the number of CSs in this group was greater than in the controls $(21 \%, p<0.01)$. More index cases had a history of atonic postpartum haemorrhage $(46$ vs. $4 \%, p<0.001)$ and placenta praevia ( 34 vs. $4 \%, p<0.01$ ). More cases than controls were delivered by CS ( 73 vs. $29 \% ; p=0.003$ ). The leading indications for EPH were haemorrhage due to uterine atony and
\end{abstract}

placenta praevia. Independent risk factors were older age, multiparity, history of one or more CSs and placenta praevia. There were 2 maternal deaths from coagulopathy following massive obstetric haemorrhage. The main complications of EPH were febrile morbidity: 12 (21\%), wound infection: 8 (14\%) and bladder or ureteric injury: 8 (14\%). Conclusions: CSs, especially repeat CSs in women with placenta praevia and persistent uterine atony, significantly increased the risks of peripartum hysterectomy.

Copyright $\odot 2011$ S. Karger AG, Basel

\section{Introduction}

Emergency peripartum hysterectomy (EPH) is defined as a hysterectomy performed at the time of delivery or in the immediate postpartum period. It is mostly performed as a lifesaving procedure in the case of persistent obstetric haemorrhage due to uterine atony, placental disorders, uterine rupture, lacerations during caesarean section (CS), fibroids or infections. The first successful operation was performed in 1876 [1].

The increasing rate of CSs worldwide and the concomitant rise in placenta praevia and accreta have resulted in an ever increasing incidence of EPH worldwide. The incidence of EPH varies from 0.3 to 1.6 per 1,000

\section{KARGER}

Fax +4161306 1234

E-Mail karger@karger.ch

www.karger.com
(C) 2011 S. Karger AG, Basel

$1011-7571 / 12 / 0213-0217 \$ 38.00 / 0$

Accessible online at:

www.karger.com/mpp
Rachana Chibber, Associate Professor

Department of Obstetrics and Gynaecology

Faculty of Medicine, Kuwait University

PO Box 24923, Jabriya 13110 (Kuwait)

Tel. +965 2531 9601,E-Mail rachana_chibber@yahoo.co.uk 
Table 1. Characteristics of index cases and controls

\begin{tabular}{|c|c|c|}
\hline Variables & $\begin{array}{l}\text { Study group } \\
(\mathrm{n}=56)\end{array}$ & $\begin{array}{l}\text { Control group } \\
(\mathrm{n}=112)\end{array}$ \\
\hline Age, years & $36 \pm 5.7$ & $22 \pm 5.3$ \\
\hline \multicolumn{3}{|l|}{ Parity } \\
\hline 0 & $3(5.3)$ & $58(51.7)$ \\
\hline 1 to $<5$ & $23(41.0)$ & $32(28.5)$ \\
\hline 5 to $<12$ & $30(53.5)$ & $3(2.7)$ \\
\hline \multicolumn{3}{|l|}{ Race } \\
\hline Kuwaiti + Bedouins & $35(62.5)$ & $48(43.3)$ \\
\hline Asians & $9(16.0)$ & $23(20.0)$ \\
\hline Other Arabs & $12(21.4)$ & $41(36.7)$ \\
\hline Body mass index, $\mathrm{kg} / \mathrm{m}^{2}$ & $22 \pm 13.2$ & $24.8 \pm 7.4$ \\
\hline Gestational age, weeks & $35.1 \pm 1.7$ & $38.4 \pm 2.9$ \\
\hline \multicolumn{3}{|l|}{ Mode of delivery } \\
\hline Vaginal & $15(26.7)$ & $80(71)$ \\
\hline $\mathrm{CS}^{\circ}$ & $41(73.2)$ & $32(29)$ \\
\hline Previous CS & $37(66.0)$ & $23(20.5)$ \\
\hline Blood loss, ml & $3,467 \pm 2,110$ & $303 \pm 109$ \\
\hline Birth weight, g & $2,257 \pm 1,144$ & $3,152 \pm 619$ \\
\hline
\end{tabular}

Figures in parentheses are percentages.

deliveries in developed countries [2-6] and may be higher in developing countries $[7,8]$. The purpose of this preliminary study in Kuwait was to estimate the incidence, indications, risk factors and complications associated with EPH performed in a tertiary teaching hospital in Kuwait.

\section{Materials and Methods}

This was a retrospective case-control study. The cases consisted of all women who underwent EPH between January 1983 and January 2011. The years 1990 and 1991 were excluded because of the Iraqi invasion of Kuwait. Two controls per case were randomly selected from the remaining deliveries by using a random number table. All cases were identified from the delivery registers, which contain a record of all consecutive births in the hospital. Case records were retrieved from the medical records.

A case was defined as a patient who had an EPH for a haemorrhage that was unresponsive to all other treatment modalities. Deliveries of less than 24 weeks gestation were excluded from the study.

The following data were recorded: maternal sociodemographic details, past medical, surgical and obstetrical histories, present pregnancy, labour and delivery events, including gestational age, mode of delivery, indications of CS and type of hysterectomy performed. Other records collected were: any additional procedures adopted, blood loss, blood transfusions, postoperative complications. Blood loss was estimated by evaluating the patient's haemo-
Table 2. Indications for CS

$\begin{array}{lll}\begin{array}{l}\text { Cases } \\ (\mathrm{n}=41)\end{array} & \begin{array}{l}\text { Controls } \\ (\mathrm{n}=32)\end{array} & \begin{array}{l}\mathrm{p} \\ \text { value }\end{array}\end{array}$

\begin{tabular}{llll}
\hline $\begin{array}{l}\text { Emergency } \\
\text { Primary }\end{array}$ & & & \\
$\quad$ APH (placenta praevia) & $6(14.6)$ & $2(6.3)$ & \\
$\quad$ Abruptio & $1(2.4)$ & $1(3.1)$ & \\
$\quad$ Fetal distress & $1(2.4)$ & $9(28.1)$ & \\
$\quad$ Malpresentation & $1(2.4)$ & $6(18.8)$ & \\
Repeat CS & & & \\
$\quad$ APH & $17(41.5)$ & $4(12.5)$ & $<0.01$ \\
\cline { 2 - 5 } Subtotal & $26(63.4)$ & $22(68.8)$ & \\
\hline
\end{tabular}

\section{Elective}

CS with placenta praevia $\quad 12(29.3) \quad 2(6.3) \quad<0.01$

Placenta praevia $\quad 2(4.9) \quad 1(3.1)$

Previous $\geq 2$ CS $\quad 1(2.4) \quad 7(21.8)$

Subtotal $\quad 15(36.6) \quad 10(31.3)$

Total $41(100) \quad 32(100)$

Figures in parentheses are percentages. $\mathrm{APH}=$ Antepartum haemorrhage. dynamic status, serial intra-operative haemoglobin by the anaesthetist and blood-soaked swabs and linen and blood collected in the kidney trays.

Febrile morbidity was defined as a temperature of $>38^{\circ} \mathrm{C}$ measured at least $24 \mathrm{~h}$ after the hysterectomy and repeated at least once.

Differences between cases and controls were compared with the $\chi^{2}$ test, Fisher's exact test and Student's t tests. Multiple logistic regression analysis was performed to identify independent risk factors for EPH. Crude and adjusted odds ratios (ORs) and their 95\% confidence intervals (CIs) were computed for identified risk factors; $\mathrm{p}<0.05$ was considered statistically significant.

\section{Results}

In the 26 years under review, there were 150,973 deliveries and 16,844 CSs. Thus the overall CS rate was $11.5 \%$. Fifty-nine women had EPHs, giving a rate of $0.39 \%$ per 1,000 deliveries. Of the 59 cases, 3 files were missing, hence 56 were analysed.

Baseline characteristics of the women who had EPHs and controls are shown in table 1 . A greater number of cases were older women (mean age $36 \pm 5.7$ years vs. 22 \pm 5.3 years, $\mathrm{p}<0.01)$. Fifty $(89 \%)$ of the cases were multiparous $(\mathrm{p}=0.02)$ and 35 were Kuwaitis $(63 \%)(\mathrm{p}<0.01)$. Thirty-seven (66\%) had had previous CSs; this number was greater than in the controls $(n=25,22 \%, p<0.01)$. 
Fig. 1. Indications for $\mathrm{EPH}$.

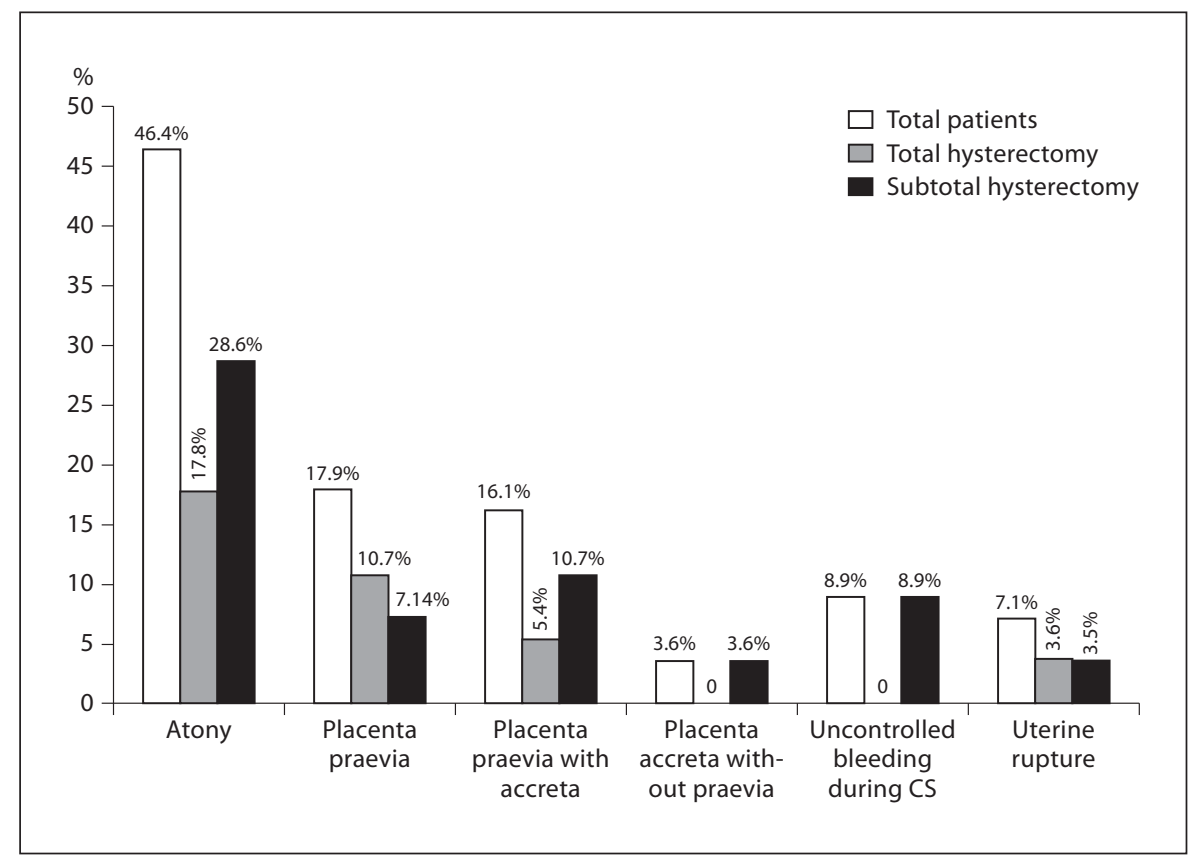

More index cases had atonic postpartum haemorrhage (PPH): 26 (46\%) versus $5(4 \%)(\mathrm{p}<0.001)$; placenta praevia: $30(73 \%)(\mathrm{p}<0.01)$; CS: $41(73 \%)(\mathrm{p}=0.003)$, and a larger amount of blood loss: 3,467 $\pm 211 \mathrm{ml}(\mathrm{p}<$ $0.001)$. Similarly, cases were delivered earlier (35.1 \pm 1.7 weeks, $\mathrm{p}=0.01)$ and thus had lighter babies $(2,257 \pm$ $1,144 \mathrm{~g}, \mathrm{p}=0.01)$. There was no difference in body mass index between the cases $(22 \pm 13.2)$ and the controls (24.8 \pm 7.4$)$.

The indications for CS (mostly emergency) in both groups are given in table 2 . The number of both emergency and elective repeat CSs with placenta praevia was greater in the index cases: $30,73 \%(\mathrm{p}<0.01)$.

As shown in figure 1, the leading indications for EPH was haemorrhage due to uterine atony: $26(46.4 \%)$ and placenta praevia \pm accreta: 19 (34\%) (pathologically confirmed). This was followed by uncontrolled bleeding during CS: 5 (8.9\%); placenta accreta without praevia: 2 (3.6\%), and uterine rupture: 4 (7.1\%).

The international recommendations for $\mathrm{PPH}$ management are generally adhered to in this hospital, including the administration of oxytocin and ergometrine preparations as first-line medical management in all cases. Corboprost (Hemobate, Upjohn, USA), a synthetic prostaglandin analogue, was used in $34(60 \%)$ cases. Blood products transfused included red blood cells: median quantity 16.73 units (SD 9.7, range 4-30 units); fresh frozen plasma: median quantity 6.8 units (SD 2.6, range
3-12 units); platelet pools: median quantity 1.8 units (SD 1.2 , range $0-4$ units); cryoprecipitate: median quantity 6.2 units (SD 7.3, range 0-20 units). The median number of red blood cells transfused was 20.1 units.

Surgical conservative measures included suturing of the placental bed: 18 (32.6\%); insertion of a uterine balloon: 11 (20\%); placement of a B-Lynch brace suture: 3 (6\%); internal iliac artery ligation: 3 (5\%), and uterine artery embolization: 4 (8\%). Subtotal hysterectomy was performed in $35(63 \%)$ of the cases with $45(80 \%)$ performed during off-duty hours, usually in the evening or at night. Forty-eight $(86 \%)$ of the EPHs were carried out at the time of CS. All EPHs were done by senior consultants. Blood loss was significantly greater in the total than in the subtotal hysterectomy group (4,650 vs. 2,678 $\mathrm{ml}, \mathrm{p}=0.03$ ).

Details on common morbidities associated with EPH were febrile morbidity: 12 (21.1\%); wound infection: 8 (14.2\%); bladder or ureteric injury: 8 (14.1\%); coagulopathy: 6 (10.7\%); urinary tract infection: 2 (3.5\%), and paralytic ileus: 2 (3.5\%) (fig. 2). Postpartum psychiatric illness occurred in 4 (7\%) cases and was successfully treated by counselling and consultations. Coagulopathy secondary to haemorrhage occurred in $6(10.7 \%)$ of cases. This was treated by extensive transfusions of whole blood, and blood factors including factor VIIa. In spite of aggressive treatment, 2 patients (33\%) died. 
Fig. 2. Morbidity associated with EPH (total of 44 complications in 56 women).

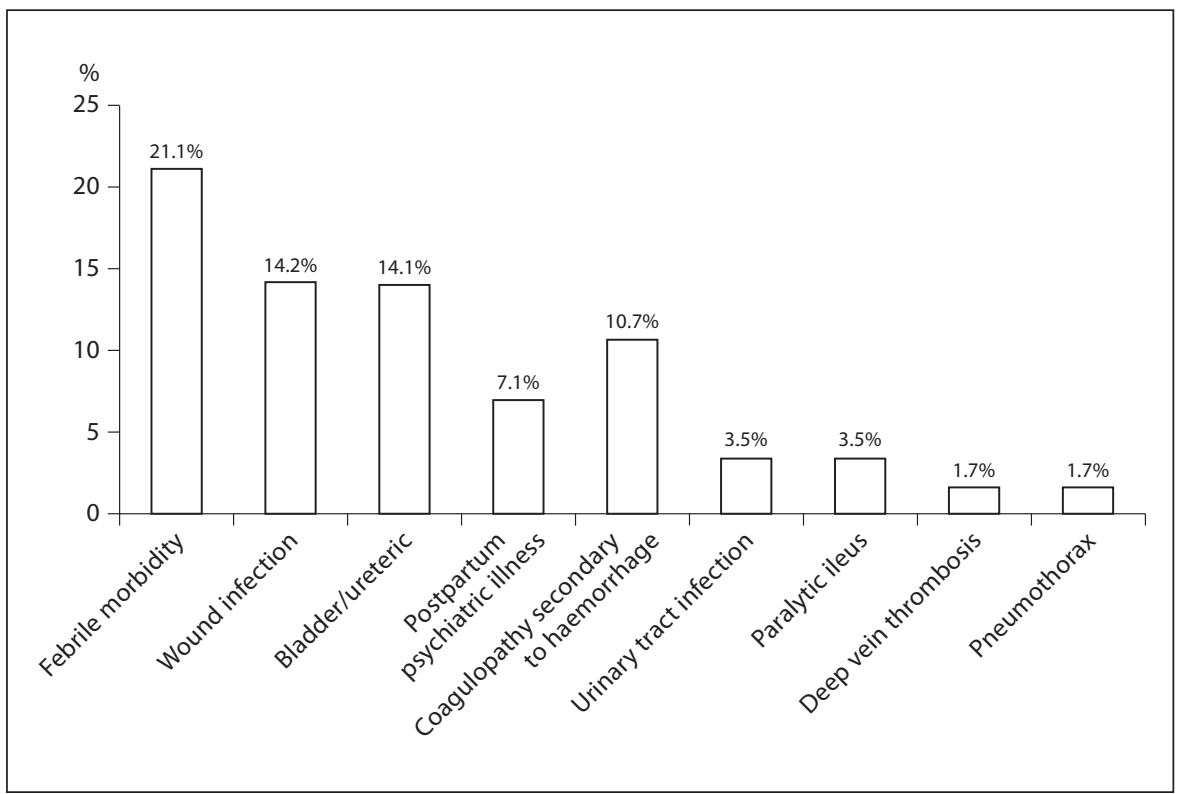

After adjusting for corresponding variables, the risk factors for EPH were older age (OR 1.2, 95\% CI 1.1-1.6), multiparity (OR 2.6, 95\% CI 1.3-10.2), history of previous $\mathrm{CS}(\mathrm{OR}=13.5,95 \%$ CI $2.7-65.4)$, CS in the index pregnancy (OR 11.6, 95\% CI 2.1-68.6) and CS delivery for placenta praevia in the index pregnancy (OR 18, 95\% CI 3.6-69).

\section{Maternal Mortality}

There were 2 (5\%) maternal deaths in this series. Both patients developed disseminated intravascular coagulopathy in the intensive care unit following subtotal hysterectomy due to placenta accreta and uterine rupture in each case. Both cases were associated with massive haemorrhage and were given generous blood transfusion, procoagulants inclusive of factor VIIa and other supportive measures. Both died within $48 \mathrm{~h}$ of the operation.

\section{Histopathology}

Of the uterine specimens, 11 (20\%) revealed the presence of adherent placenta on histopathologic examination. In 10 women, the placental adhesion occurred at site of the CS scar with associated placenta praevia. Uterine fibroids were found in 8 specimens; their sizes ranged from 5 to $8 \mathrm{~cm}$. Four other patients had placenta praevia in an unscarred uterus. The remaining uteri were histologically normal.

\section{Discussion}

Peripartum haemorrhage is truly one of the most menacing life-threatening conditions in obstetrics. Our EPH incidence of 0.39 per 1,000 deliveries compares favourably with those quoted from developed countries [26]. Much higher rates of 2.7 per 1,000 deliveries have been reported from developing countries [7-10]. The cutoff point at which hysterectomy becomes necessary is subjective and ill-defined. There are no formal guidelines on the stepwise use of conservative measures prior to resorting to hysterectomy or on the absolute trigger for hysterectomy.

The association between the rising CS rate and incidence of EPHs with a history of CS is mostly attributable to the occurrence of adherent placenta [11-14]. We found a definite rise in the incidence of placenta accreta as the primary indication for EPH over the last 6 years.

Our study showed that all of our cases had a history of at least 1 CS. The CS rate in this hospital rose from $8.1 \%$ in the 1980 to $11.15 \%$ in early 2010 and then to $20.5 \%$ from early 2011 . The risk of placenta accreta increases linearly with the number of previous CSs, and is as high $67 \%$ in women with more than 3 previous CSs $[15,16]$ similar to $70 \%$ of placenta accreta in women with 3 or more CSs in this study. In the Middle East, large families (8-12 children) are not unusual, nor is it uncommon that women do become pregnant after 4 or more CSs [17]. 
During the first decade of the study by Flood et al. [6] (1966-1975), haemorrhage due to uterine atony was the leading indication as was also the case in the present series with $46 \%$. The high rate of uterine atony requiring an EPH could be due to the fact that a large number of patients were grand multiparas or women with little or no antenatal care. These women often came in prolonged obstructed labour, and were anaemic, dehydrated and exhausted. However, in recent times, abnormalities of placentation have emerged as the most common indication for EPH $[15,16]$, and in this series it was a close second indication (35\%). The reason for this shift was attributed to increased success of treatment with uterotonic agents, prostaglandins, embolization, uterine catheters, and surgical procedures such as the B-Lynch technique [12] or selective devascularisation. Only $4(8 \%)$ women had successful uterine artery embolization, which is a recognised effective technique [3] to control obstetric haemorrhage. Internal artery ligation was done by the vascular surgeons and $5 \%$ of the index cases were fit to undergo and benefit from this procedure.

Starting in the second decade of our study, we found a significant downward trend in the incidence of uterine rupture as the indication for EPH. Uterine rupture featured more significantly in the earlier decade, similar to findings of earlier studies on the incidence of EPH [18, 19]. This significant decrease is most likely the result of changes in modern obstetric practice, with more judicious use of oxytocin, and trials of labour in the setting of previous CS. Thus, there was only 1 case of EPH because of a uterine rupture with a history of a previous CS in the last 10 years. Our findings are consistent with a those of studies performed in Saudi Arabia [17], Turkey [20] and the UK [21].

Since the last decade, we have used antenatal coloured Doppler sonography to identify women with placenta praevia and a previous CS to assess variable vascular morphologic patterns of abnormal placentation. Magnetic resonance imaging (MRI), in conjunction with ultrasound is now being used successfully at our institution for antepartum diagnoses of placenta accreta and bladder involvement. In cases where imaging modalities suggest invasive placentation, our patients are adequately counselled and prepared for a possible hysterectomy. Diagnostic modalities such as MRI and lifesaving blood factors such as factor VIIa are available in Kuwait since the last 5-7 years, and have resulted in averting many obstetric haemorrhagic disasters at this institution.

Peripartum Hysterectomy
In this study, the risk of EPH increased 11-fold when a woman had a CS, similar to other studies $[6,15]$ in which $45-95 \%$ of EPHs were in women delivered by CS. The observation that CS for placenta praevia increased the risk of hysterectomy 18 -fold was similarly reported by Bakshi and Meyer [22] with the risk being increased as high as 110 -fold.

Expectedly, EPH is associated with extensive blood loss (table 1) and thus the need for the transfusion of large volumes of blood and blood products. Even though preservation of fertility is of paramount importance in this part of the world, attempts at fertility-sparing conservative management should not be unduly prolonged as this increases the risk of further blood loss, coagulopathy and maternal mortality as illustrated by both our patients that died.

There is often a debate regarding the benefits of subtotal versus total hysterectomy. Our study found a trend toward the preference for subtotal procedures and that the incidences varied greatly in recent studies $[6,13,15$, $16]$. It has been suggested that total hysterectomy is preferable where practicable $[6,14]$. Indeed, subtotal hysterectomy may not always be sufficient to abate the haemorrhage, especially from the cervical branch of the uterine artery. However, other studies $[13,15,16]$ have shown that there is no difference in blood loss or transfusion rates between total and subtotal procedures. Arguments for the performance of subtotal hysterectomies include findings of shorter operation times and hospitalization. We consider subtotal hysterectomy a much faster and technically safer procedure in desperately ill patients and those who have massive adhesions over the lower uterine segment involving the urinary bladder as exemplified in the 2 desperately ill patients who were bleeding heavily in our series.

Intra- and postoperative complications are associated with EPH. The high rate of $78.5 \%$ complication in our series confirmed the study of Engelsen et al. [14] in which 34 complications were observed in 11 women. Equally important, severe psychiatric illness noted in our study was also reported by Engelsen et al. [14].

The commonest complication of $21 \%$ due to febrile morbidity was also noted by Selo-Ojeme et al. [15]. Eight of the complications in the total-hysterectomy group may be due to the difficulties of the procedure rather than operator experience as all the procedures were performed by senior obstetricians.

The strength of this study lies in the cohort of cases reported over 26 years and being a preliminary report of over a quarter century from the State of Kuwait. The con-

Med Princ Pract 2012;21:217-222 
straints include our inability to determine whether the widely prevalent practice of ingesting herbal medications for postpartum haemorrhage, prior to hospital admission, influenced uterine atony, which was unresponsive to conservative treatment, All the more so as uterine atony was the leading cause of EPH.

\section{Conclusions}

Uterine atony emerged in our study as the primary indication for EPH with abnormal placentation, a close second. In the majority of cases, anticipation, prompt resuscitation and earlier surgical intervention by a skilled operator will reduce patient morbidity and mortality.

\section{References}

$\checkmark 1$ Plauché WC, Gruich FG, Bourgeois MO: Hysterectomy at the time of caesarean section. Obstet Gynaecol 1981;58:459-464.

-2 Gun Gord K, Yildirim G, Dugan N, Polat S: Peripartum hysterectomy in Turkey: a case control study. J Obstet Gynaecol 2009;29: 722-728.

3 Zwart JJ, Dijk PD, Rooshmalen JV: Peripartum hysterectomy and arterial embolization for major obstetric hemorrhage: a 2-year nationwide cohort study in the Netherlands. Am J Obstet Gynaecol 2010;21:150.e1-150. e7.

4 Awan N, Bennett MJ, Walters WA: Emergency peripartum hysterectomy: a 10-year review at the Royal Hospital for Women, Sydney. Aust NZ J Obstet Gynecol 2011;3:210215.

-5 O'Brien D, Babiker E, O'Sullivan O, Conroy R, McAuliff F, Geary M, Byrne B: Prediction of peripartum hysterectomy and end organ dysfunction in major obstetric haemorrhage. Eur J Obstet Gynaecol Biol 2010;153: 165-169.

6 Flood KM, Said S, Geary M, Robson M, Fitzpatrick C, Malone FD: Changing trends in peripartum hysterectomy over the last 4 decades. Am J Obstet Gynecol 2009;2:632.e1632.e5.

7 Rabiu KA, Akinlusi FM, Adewunmi AA, Akinola OI: Emergency peripartum hysterectomy in a tertiary hospital in Lagos, Nigeria: a five-year review. Trop Doct 2010;40 $1-4$.
8 Seffah JD, Kwame-Aryee RA: Emergency peripartum hysterectomy in the nulliparous patient. Int J Gynaecol Obstet 2007;97:4546.

9 Okafor UV, Ezegwulh U, Okezie O: Anaesthetic challenges in emergency peripartum hysterectomy in West Africa: a Nigerian perspective. S Afr J Anaesth Analg 2010;16:811.

10 Shah N, Khan NH: Emergency obstetric hysterectomy: A review of 69 cases. Rawal Med J 2009;34:75-78.

-11 Henrich W, Surbek D, Kainer F, Grottke O: European Guidelines to treat massive obstetric haemorrhage. J Perinat Med 2008;36: 467-478.

12 Lynch CB, Coker A, Lawal AH: The B-Lynch surgical technique for control of massive postpartum haemorrhage: an alternative to hysterectomy? Five cases reported. Br J Obstet Gynaecol 1997;104:372-376.

13 Rehman J, Al-Ali M, Qutub HO: Emergency obstetric hysterectomy in a University hospital: a 25-year review. J Obstet Gynaecol 2008; 28:69-72.

14 Engelsen BE, Albrechtsen S, Iverson OE: Peripartum hysterectomy incidence and maternal morbidity. Acta Obstet Gynaecol Scand 2001;80:409-412.

15 Selo-Ojeme DO, Bhattacharjee P, IzuwaNjoku NF, Kadir RA: Emergency peripartum hysterectomy in a tertiary London hospital. Arch Gynecol Obstet 2005;271:154159.
16 Kwee A, Bots ML, Visser GHA, Bruinse HW: Emergency peripartum hysterectomy: a prospective study in The Netherlands. Eur J Obstet Gynecol 2006;124:187-192.

- 17 Al-Suleiman SA, Al-Sibai MH, Al-Jama FE El-Yahia AR, Rehman J, Rahman MS: Maternal mortality: a twenty-year survey at the King Faisal University Hospital, Al-Khobar, Eastern Saudi Arabia. J Obstet Gynaecol 2004;24:259-263.

18 Orbach A, Levy A, Wiznitzer A, Mazor M, Holcberg G, Sheiner E: Peripartum cesarean hysterectomy: critical analysis of risk factors and trends over the years. J Matern Fetal Neonatal Med 2011;24:480-484.

19 Forna F, Miles AM, Jamieson DJ: Emergency peripartum hysterectomy: a comparison of cesarean and postpartum hysterectomy. Am J Obstet Gynecol 2004;190:1440-1444.

20 Karayalcin R, Ozcan S, S Mollamahmutoglu L, Danisman N: Emergency peripartum hysterectomy. Arch Gynecol Obstet 2011;283: 723-727.

21 Knight M, Kurinczuk JJ, Spark P, Brocklehurst P: Cesarean delivery and peripartum hysterectomy. Obstet Gynecol 2008;111:97105.

22 Bakshi S, Meyer BA: Indications for and outcomes of emergency peripartum hysterectomy. A five-year review. J Reprod Med 2000; 45:733-737. 